\title{
Working Holidays for Overseas Doctors: Host Perspective in Mission Hospitals in Rural India
}

\author{
Jesudian Gnanaraj ${ }^{\mathrm{a}}$ \\ a MS [Gen], MCh [Urology], DMS, Director of Medical Services, Surgical Services Initiative, Association of Rural \\ Surgery, Tamil Nadu, India
}

\begin{abstract}
Many doctors are willing to spend part of their holidays helping mission hospitals. Some are senior physicians who can contribute a great deal to the program. We describe how it was possible to use their time effectively. We also describe some of the difficulties encountered and the benefits that were obtained from their efforts.

Junior doctors helped mission hospitals in many ways, doing a variety of studies and preparing the protocols for the hospital to use. Senior doctors introduced procedures like vaporization surgery and Lift laparoscopic surgery that benefitted rural patients greatly. They also taught new procedures and helped with the publication of research findings. The visitors benefitted as well, a win-win situation.
\end{abstract}

\section{Introduction}

Mission Hospitals in India in their heyday possessed adequate resources and skilled and committed manpower. They were able to provide ethical and appropriate healthcare to the communities they were to serve. With the withdrawal of missionary support and the paucity of funds as well as of updated and skilled medical professionals, sustainability of mission hospitals has been a concern. ${ }^{1}$ A solution to this impasse has been to facilitate skilled healthcare professionals to be able to take time off from their busy schedules, bringing their expertise, benefitting a whole new community. ${ }^{2}$

Mission hospitals offer a great opportunity to serve the poor and the needy by using God given talents, especially for senior doctors. Many senior doctors are willing to spend part of their holidays doing mission or social service. Medical students and junior doctors are looking for hands on experience during their holidays. The rural and mission hospitals need to upgrade their skills and facilities to be relevant to the communities that they serve. Proper planning and networking could help both visitors and hospitals to benefit greatly. We present how we were able to do this in mission and rural hospitals in India. We also present the difficulties we faced and the benefits demonstrated by the presence of both junior and senior level doctors.

\section{Methods}

Visitors to Burrows Memorial Christian Hospital [BMCH] and Samiti for Education, Environment, Health and Social Action [SEESHA] during the last 12 years were recruited from the following groups:

A. Former surgeons or doctors who worked at the hospitals

May 2015. Christian Journal for Global Health 2(1): 35-42. 
B. Members of the churches of the overseas visitors or missionaries to the hospitals

C. Doctors met at various conferences where we had made presentations

D. Relatives of local staff and visitors

E. Doctors who contacted us after looking at our website or articles

F. Students who came through university exchange programs

The process of recruitment or invitation involved letting the visitors know exactly what we are doing and what we expected from them well before their arrival. Information on dress codes and experiences of previous visitors were sent to them. ${ }^{3}$ We obtained donated medical supplies from places like Medwish and Rays of Hope international. ${ }^{4,5}$ Information about these sources were sent to the visitors, and the sources were informed about the visitors. Videos about the hospital were sent to the visitors. ${ }^{6}$

Medwish provides disposables and other small items that can be hand carried in a suitcase. They have a handling charge of about one or two dollars per pound of supplies. We have former missionary children [now Pastors, etc.] who help us obtain these items, pack them in suitcases, and send them to the visitors. Most of these volunteers are non-medical personnel, and pictures of the disposable items that are needed are helpful when picking them up. We have identified items that can be used at the hospital. Before we provided illustrations, many items that were brought could not be used.

Other than doctors of Indian origin and overseas doctors with permanent licenses to practice in India, visitors require temporary registration with the Medical Council of India [MCI]. This temporary registration is through the sponsoring hospital or institute; forms must be submitted: forms MCI 07 and Rs. 5000. Those who come to India to learn are registered separately. The application is available from the MCI website. $^{7}$

Medical students, junior doctors, and others who come to learn take an on-line course to give them some background knowledge. ${ }^{8}$ Topics for their research project are assigned. Completed projects are published.

\section{Results}

Visitors to BMCH and SEESHA came from the following places [Table 1] and trained in the following specialties [Table 2].

Table 1. Counts of physicians by sending country

\begin{tabular}{lc}
\hline Country & Number of Doctors \\
\hline USA & 9 \\
Germany & 3 \\
Nigeria & 7 \\
Switzerland & 2 \\
Singapore & 2 \\
UK & 5 \\
Canada & 1 \\
Australia & 1 \\
\hline
\end{tabular}

Table 2. Counts of physicians by specialty

\begin{tabular}{lc}
\hline Specialty & Number of Doctors \\
\hline Urologists & 1 \\
Laparoscopic surgeons & 4 \\
General surgeons & 3 \\
Gynecologist & 2 \\
Rural surgeons & 5 \\
General physicians & 3 \\
Endocrinologist & 1 \\
Residents and Interns & 11 \\
\hline
\end{tabular}

\section{Principles Learned}

Working alone at a mission hospital for years without much accountability can tempt surgeons to compromise to get work done more quickly or to try to manage without appropriate supplies. For example, if a sufficient number of drapes are not available they would manage with the available number. If instruments become unsterile, they might put them in Cidex [Gluteraldehyde] solution rather than autoclaving them and waiting. The overseas surgeons would refuse to make compromises like these. Working with them helped the operating staff encourage local surgeons not to compromise. 
The operating room staff noticed that the visiting surgeons never seemed to be in a hurry. They seemed to have all the time in the world for the particular patient on which they were operating. This is different from the mindset of mission hospital surgeons often in a hurry to finish the operation.

Learning to say "No" is a very difficult thing for a mission hospital surgeon. The fact that many of the patients whom they treat have no other place to go makes saying no even more difficult. The overseas surgeons, including African colleagues, were comfortable saying no.

\section{Techniques Introduced}

Overseas doctors introduced vaporization of the prostate. Previously, we had performed transurethral resection of prostates. This often required that a unit of blood be obtained prior to the procedure, the anticipation of complications due to bleeding, and the risk of blocked catheters. Vaporization of prostate is almost bloodless, there was no need to arrange blood, and surgeries are able to be done during surgical camps. ${ }^{9}, 10$ Because there was no significant bleeding and vision remained clear during surgery, many general surgeons were able to learn the procedure. The procedure was able to be done at 19 other mission or rural hospitals.

Laparoscopic surgery has many advantages for poor patients. Often, they are the sole breadwinners for the family and need to get back to work as soon as possible. However, the high cost of laparoscopic surgery is a major constraint in rural areas. Several methods of cost reduction were attempted. ${ }^{11}$ General anesthesia cost is often more than ten times that of spinal anesthesia. Both hospital and patients benefitted when a team from Germany came to demonstrate gasless Lift laparoscopic surgeries. ${ }^{12,13}$ These procedures had benefits other than being done under spinal anesthesia. Traditional open surgical instruments could be used. The equipment is sturdy and easy to use. Live surgery workshops were arranged at Coimbatore and Midnapore Medical colleges and during The Association of Rural Surgeons of India conferences.

\section{New Procedures and Equipment}

When most of the current senior doctors in mission hospitals received their surgical training, laparoscopic surgeries were not in use in the medical colleges, and these techniques were not taught. As the numbers indicate, more laparoscopic-surgeons visited the mission hospitals to teach laparoscopic surgeries. Hence, the presence of a senior laparoscopic surgeon at the mission hospital is of great help to the mission hospital surgeon.

Endometrial vaporization is a minimally invasive procedure for dysfunctional uterine bleeding, and its introduction to mission hospitals helped many patients. ${ }^{14}$ Overseas doctors taught simple and easy techniques to perform procedures for cleft lip and palate.

In mission hospitals, general surgeons often carry out orthopedic procedures and overseas orthopedic surgeons came with instrument sets they donated to the hospital. In fact, most of the overseas surgeons brought surgical instruments and taught the local surgeons how to use them. These were often donated by institutions back home. These would have been prohibitively expensive for the mission hospital to buy. Such equipment included a gastroscope, laparoscopic hand instruments, electro-cautery machine, etc.

\section{Publications}

Several new, important, and useful methods have been practiced in rural mission hospitals. For instance, at BMCH in the fifties, proctoscopes were used for taking biopsies from the abdomen for ruling out/confirming tuberculosis. Sterile ping pong balls were used for collapse therapy when there was haemoptysis.

Mission hospital doctors generally do not have the time or the inclination to publish papers. However, overseas doctors were eager to publish the findings. They helped in writing the papers, correcting the papers, drawing out the pictures, etc. ${ }^{15,16}$ 
When we started doing laparoscopic surgeries, we had only a trained nurse anesthetist giving anesthesia. He was most comfortable using ether and the Ebstein and Macintosh of Oxford [EMO] machine for anesthesia. Although we attempted early surgeries with our Boyle's machine, we later were forced to shift to anesthesia with ether and EMO machine. We had searched on the internet to find out if anyone had done laparoscopic surgeries with ether and EMO but could not find any papers. Once we pub- lished about this, I received many e-mails from other parts of India and from African countries thanking us for publishing that laparoscopic surgeries were possible with ether anesthesia. Table 3 lists the references for some of the publications of the visitors to the mission hospitals.

The publication topics varied from medicine to microbiology to computers to surgical procedure. The variety was, possibly, primarily due to the interest of the visitors.

\begin{tabular}{|c|c|}
\hline Journal & Topics \\
\hline Australian and New Zealand Journal of Surgery & Transurethral vaporization of prostate \\
\hline Tropical Doctor & $\begin{array}{l}\text { 1. Appendectomy with cystoscopy } \\
\text { 2. Single incision gas less laparoscopic appendectomies }\end{array}$ \\
\hline Indian Journal of Surgery & Diagnostic and surgical camps \\
\hline International Journal of Infertility and Fetal Medicine & Single incision gas less laparoscopy and other MIS for infertility \\
\hline Christian Journal for Global Health & Surgical work in medical missions \\
\hline CHRISMED Journal of Health and Research & $\begin{array}{l}\text { 1. Surgical Services Initiative } \\
\text { 2. Feasibility of laparoscopic surgeries in rural areas }\end{array}$ \\
\hline Journal of Association of Physicians of India & Survey of diabetes in remote rural population \\
\hline Journal of Pure and Applied Microbiology & Uropathogens in tribal and tea garden workers \\
\hline Rural Surgery & $\begin{array}{l}\text { 1. Minimally invasive appendectomies } \\
\text { 2. Computers for rural surgeons } \\
\text { 3. Cystoscopic removal of esophageal coin } \\
\text { 4. System Audit for small hospitals } \\
\text { 5. Survey of laparoscopic facilities in rural areas }\end{array}$ \\
\hline MD Current India & $\begin{array}{l}\text { 1. Cost effective treatment of renal stones in rural areas } \\
\text { 2. Instruments for Lift laparoscopic surgery }\end{array}$ \\
\hline Christian Medical Association of India & Choosing software for rural hospitals \\
\hline
\end{tabular}

\section{Financial Gains}

Visiting surgeons paid their own travel expenses, some of them sponsored diagnostic camps, and many of them gave donations to specific projects at the hospital. In return, the hospital was able to arrange for sightseeing at locations not available to regular tourists. There are often remote locations where the only decent places to stay are the government tourist bungalows; local contacts are necessary for booking them. The use of hospital vehicles and the hospitality of hospital contacts made it easier for the visitors.
The visitors enjoyed access to areas where tourists often are not allowed, like the inside of Dams and helicopter and boat rides etc. These were possible because they came to help the poor in that area.

The people who benefitted most were the poor and marginalized patients from rural areas. On an average, patients paid about Rs. 12000 (\$200) for laparoscopic hysterectomies or myomectomies. Visiting surgeons brought a variety of scopes they used and left behind. If we had purchased them locally, just the cost of the disposable handle for vessel sealing would have cost 
about Rs. 48000 (\$800). Local hospitals are unlikely to have bought them due to the high cost and unlikelihood of recouping the expense.

\section{Professional Gain for Visitors}

Many of the visitors were able to have hands on experience in the operating room and with diagnostic procedures like gastroscopy, cystoscopy, ultrasound examination, etc. Many were happy with the opportunities for publications possible because they wrote up the work done at the hospital.

\section{New Insights}

Many mission hospitals do not consider new initiatives unless encouraged by visiting doctors. For instance, when an endocrinologist from Australia visited us, she was surprised to see a thin active patient from a remote tribal area with diabetes. After going through further records, she requested that we systematically study the remote tribal population. ${ }^{17}$ This article is quoted often, as it shows a high incidence of diabetes in a thin hard working non-sedentary tribal population. This helped the hospital plan an outreach program for those people.

\section{Spiritual Insights}

In general, when we look at a patient with a condition (say a Gallstone or Kidney stone) that we can cure by surgery, our faces light up. On the other hand, when we see someone with a disseminated malignancy, our faces droop. This was not so with our missionary surgeon. His face was always lit as he considered every patient a person who needs to hear the good news and get to heaven. His hugs made the patients forget their disease and become happy.

We learned the power of prayer as our missionary surgeons taught us to pray always, and we learned the benefits of prayer for even the patients under anesthesia. There was a patient who had failed an attempt to remove a right renal calculus with a discharging sinus for 17 years, and we had offered a nephrectomy. During a break, the assisting surgeon decided to finish the surgery quickly but tore the few attachments to the vena cava. This resulted in great panic. The visiting missionary surgeon, in his eighties at that time, was called in to assist. He came and prayed with the patient's son, which we did not mind. However, when he went to pray with the patient under anesthesia, we thought it was a little too much. He came in and helped us to get the bleeding under control. We realized later that our anesthetist had switched off all anesthesia medicines and was giving only oxygen and muscle relaxant. The patient eventually said that it was Dr. Kenoyer and his God who saved her.

\section{Problems}

There were misunderstandings due to cultural differences, especially related to matters of papers and publications while working with the overseas doctors. They felt insulted if papers were sent to Journals without their seeing the final corrections. It seemed like local doctors and staff members were not to be trusted, and they wanted personally to go through all the documents, registers, and printouts. Despite not finding any discrepancies in the first paper, they still wanted to do the same thing for subsequent ones. It looked as though they felt that the Indians were not sincere in presentation of the records or findings. The overseas doctors disliked using our own references in the articles. For the local doctors, it is the most convenient thing to do, as getting other references or access to a library is very difficult.

Comments about obesity were not taken kindly. Changing the order of surgeries and not being present at the agreed upon time were considered serious offences by some visiting surgeons. Although surgery lists were prepared the previous day, they were not followed strictly due to a variety of reasons. Sometimes, the reasons might be trivial. Unlike the Indian surgeons, visiting surgeons were offended if they were called when they were not expecting a call. They did not accept approximations in timing of schedules or changes in plans. 
After the overseas visitors leave, there can be a large backlog of work. Many patients feel that overseas surgeons are better at surgery because they have handled knives and forks from childhood and many register for surgery. The visiting surgeons are often slower and also say 'no' to patients. This leaves the local surgeons with a lot of work after visiting surgeons leave.

The overseas surgeons were generally not aware of or bothered by cost. For instance, they would use 2 sets of tackers for a hernia repair to place 22 tacks when one set contains 20 tacks. This can mean a difference of Rs. 20000 (\$335) to the hospital. Patients may be offered surgery at much less cost than the usual one for the sake of recruiting more patients for camps.

Visiting surgeons felt that tying knots by hand was better than tying using instruments. This consumed more suture material. Sometimes, senior nurses would tell them that they had run out of sutures to prevent them from using too many sutures. When they found out that sutures were still present and the nurses lied to them, they became so angry that they wanted us to take serious action or even dismiss the nurses. Despite being Christians, the Indian nurses felt that they could tell a lie for a good cause (which comes from the Hindu tradition). It was difficult for the hospital to dismiss them or take serious actions because they felt that they did whatever they did with the intention of helping the hospital.

However, the major problem was that sometimes, when things were not going their way, the visiting surgeon could just dump everything and walk away. When this happened during a workshop, the local surgeons had to complete the surgeries, and it was not pleasant to operate in front of many surgeons of equal or more senior seniority. It was embarrassing to explain why the visiting surgeon was not willing to continue with the surgeries and to do the surgeries when the audience actually came to see the visiting surgeon operate.

There are small cultural differences that sometimes cause problems. The hospital staff was embarrassed by the reactions they got from visitors when the staff members said what they thought was innocuous, like mentioning someone is fat or asking their salaries, etc.

\section{Discussion}

There are formal working holiday programs, like the Australian one, which allows young people to work and study in Australia. ${ }^{18}$ Volunteering in African countries provides opportunities to serve for about a month in a teaching and training capacity, mostly in health education. $^{19,20}$ Organizations like Medicalmissions.org offer a little more, specialized volunteering experience but still are limited to simple outpatient treatment. ${ }^{16}$ Some organizations, like Missionfinder.org and Operation Hernia, offer links to specific professionals like cardiologists and general surgeons. ${ }^{18,21}$

The drawback of the above programs is that, most of the time, the specific expertise or talent of the visiting consultants is not utilized. Often, the good work by the visiting consultant does not continue. The visiting consultants are most happy when the work they initiated continues and expands. They are also happy and continue support when they hear that the equipment they donated is fully utilized.

The advantages of the working holiday model are the following:

1. It is a win-win situation for everyone involved. The visitors are happy to contribute and enjoy special sightseeing. The local doctors learn a lot. The hospital gets monetary benefit, and many poor patients benefit.

2. The visiting consultants' time can be used for training others.

3. The junior medical personnel could contribute to preparing protocols for treatment, improving the quality of services, and writing papers.

The problems related to differing expectations, different cultures, and a prior mindset of visitors about Indians might be resolved by an orientation for the visitors and the receiving hospital paying attention to details. We do now talk 
to the staff prior to the visit of senior staff regarding how to interact with them. Sometimes, good friendships have been lost for trivial things, like calling someone obese or sending a revised article for publication without showing it to them first.

However, all visitors, including those offended, felt they did contribute in a very significant way to help poor and marginalized patients. Their time at the hospital was spent in a useful way. Local surgeons felt that they learned much from the visitors but always had to be on their toes and put in a great deal of extra effort to do things they normally would not do. The hospital and the patients had nothing but positive things to say about the visitors. Careful planning is necessary for achieving the objectives if there is to be benefit from the working holiday plan.

Although none of the visitors complained about the facilities available at the hospital, most of the time, places where we stayed during diagnostic or surgical camps were far below the standards to which they were accustomed. The facilities the visitors enjoyed were very basic. It was their love for Christ, their interest in mission work, and the prayers and support of their local Church that brought them to the mission hospital. Many of them have continued to pray and support the mission work and to encourage others to come and visit. Over the years, the visitors have made a significant contribution to church growth in the area where the hospitals are situated. ${ }^{24}$

\section{References}

1. Aruldas A, Awale A, Zachariah P. Sustainability of church health care in India. World Council of Churches and The Christian Medical Association of India. 1997.

2. Rexford, Kofi, Oduro, Asante. Sustainability of church hospitals in developing countries: a search for criteria for success. World Council of Churches. 1998.

3. A trip with Seesha [internet] available from: http://www.karunya.edu/seesha krch/seesha\%20feed \%20back\%20_1_\%20_2_.pdf and Jacob T. Experi- ences with God's faithfulness in the Seesha Assam Medical Camp (April 18-21, 2011). Available from: http://www.karunya.edu/seesha_krch/Assam\%20camp \%20report\%20_1.pdf

4. MEDWISH [internet]. Cleveland, Ohio; Available from: https://www.medwish.org/

5. Rays of Hope International [internet]. Grand Rapids, Michigan. Available from: http://www.raysoh.org/

6. Burrows Memorial Hospital [internet]. Available from: https://www.youtube.com/watch?v=ca-6d0hfhw

7. Medical College of India [internet]. Available from: http://www.mciindia.org/

8. Karyuna University [internet]. Available from: http://www.karunya.edu/

9. Gnanaraj J. Gnanaraj L. Transurethral electrovaporization of prostate: a boon to the rural surgeons. Australian and New Zealand Journal of Surgery. 2007 Aug;77(8):708.

10. Gnanaraj J. Diagnostic and surgical camps: costeffective way to address the surgical needs of the poor and the marginalized. MD Current India. 2014 Jan. Available from: http://mdcurrent.in/primarycare/diagnostic-surgical-camps-cost-effective-wayaddress-surgical-needs-poor-marginalized]

11._Gnanaraj J. Laparoscopic surgeries in rural areas. Challenges and adaptations: an experience of over 1300 laparoscopic surgeries. Australian and New Zealand Journal of Surgery. 2007;77(9):799-800.

12. Gnanaraj J. Gasless lift laparoscopy. Rural surgery. 2013 Jan; 8(4):17 -9.

13. Gnanaraj J. Single Incision Lift Laparoscopic Surgeries [SILLS]: Taking modern surgery to the poor. $\mathbf{J}$ Miss 2 (3):e11465 Published online 2013 October 8 available from:

http://www.researchgate.net/publication/263040390_S ingle_Incision_Lift_Laparoscopic_Surgeries_SILLS Taking_modern_surgery to the_poor

14. Gnanaraj J, Lionel J. Endoscopic resection/vaporization: a patient friendly first option treatment for menorrhagia in rural areas. Tropical Doctor. 2008 Apr. 38:103-4 
15. Gnanaraj J, Cherk -Yun. Minimally invasive appendicectomy using cystoscope. Tropical Doctor. 2008 Jan; 38(1):14-5.

16. Gnanaraj J, Lau Xe Xiang J, Khiangte H. High quality surgical care at low cost: The Diagnostic camp model of Burrows Memorial Christian Hospital. Indian Journal of Surgery. 2007 Dec; 69(6): 243-7. http://dx.doi.org/10.1007/s12262-007-0034-0

17. Lau SL, Debarma R, Thomas N, Asha HS, Vasan KS, Alex RG, Gnanaraj J. Health care planning in North-East India: a survey of diabetes, awareness, risk factors and health attitudes in a rural community.

Journal of the Association of Physicians of India. 2009 Apr;57:305-9. Available from:

http://www.pubfacts.com/detail/19702036/Healthcareplanning-in-north-east-India:-a-survey-on-diabetesawareness-risk-factors-and-health-atti

18. Tan, Y, Richardson S, Lester L, Bai T and Sun L. Evaluation of Australia's Working Holiday Maker Program. Cited February 5, 2015 Available from: http://www.immi.gov.au/media/publications/research/ _pdf/whm-report.pdf ]
19. Cited February 5, 2015 Available from; http://www.africanimpact.com/communityvolunteering/medical/livingstone-budget-volunteeringhealthcare-and-community-development-project

20. Cited February 5, 2015 Available from; http://www.idealist.org/info/Volunteer/Resources/Trav el

21. Cited February 5, 2015 Available from; http://www.medicalmissions.org/

22. Cited February 5, 2015 Available from; http://www.missionfinder.org/

23. Cited February 5, 2015 Available from; http://www.operationhernia.org.uk/

24. Gnanaraj J and Rhodes M. Surgical work in medical missions: study in remote areas of India. Christian Journal for Global Health (November 2014), 1(2):4247. http://dx.doi.org/10.15566/cjgh.v1i2.33

Peer Reviewed

Competing Interests: None declared.

Correspondence: Jesudian Gnanaraj, SEESHA, India. ignanaraj@gmail.com

Cite this article as: Gnanaraj J. Working Holidays for Overseas Doctors: Host Perspective in Mission Hospitals in Rural India. Christian Journal for Global Health (May 2015), 2(1):35-42.

(C) Gnanaraj, J. This is an open-access article distributed under the terms of the Creative Commons Attribution License, which permits unrestricted use, distribution, and reproduction in any medium, provided the original author and source are properly cited. To view a copy of the license, visit http://creativecommons.org/licenses/by/3.0/

wWw.cjgh.org 